persist despite treatment-as the general practitioner would do.

Would simple flow charts be just as useful and cost effective? If our own experience with village health workers of Mandwa Project is any indication the diagnostic flow charts ${ }^{78}$ will never be popular among the workers despite efforts to promote their use. The reasons generally were that health workers had always to refer and cross refer to more than one flow chart for each patient and that most charts gave the probable diagnoses when it was suggestions about treatment they were most interested in. Since computers are coming in a big way, even to the remote areas of the developing world, and are being used for administration and for collecting epidemiological data we thought it desirable to develop programs for a paramedical worker that could also be used by a lay person. Eventually it may be possible to devise portable hardware so the package would be more useful in rural areas.

After the knowledge base is refined and a larger field trial carried out Sympmed I may be useful in broadening a paramedical worker's or even a lay person's knowledge and awareness of the treatment of illness. It may be used primarily for screening patients in crowded outpatients departments at rural health centres and urban dispensaries with the help of a paramedical worker directing only those patients to a doctor who need a doctor's attention most. Sympmed I is expected to help in promoting safe, informed, primary, curative care with the use of home remedies and a few essential drugs, in limiting dangerous self medication, and in reducing expenditure on trivial health problems.

We gratefully acknowledge the support of Dr Prem Gupta, chairman and managing director of CMC Ltd, in developing the program; Dr A V Hegde for help in preparing and feeding programmable algorithms; and Drs P H Keni, Ajay Keni, and Nandini Keni, and their patients, for participating and allowing us to conduct the evaluation in their dispensary. We also thank Mr D B Shingrup, the engineer who replaced the assistant doctor in the later part of the trial.

1 Antia NH. Mandwa experiment -an alternative strategy. $\mathrm{Br} \mathrm{Med} \mathcal{f}$ 1986;292: $1181-3$.

2 Schwartz WB, Patil RS, Szolovits P. Artificial intelligence in medicine: where do we stand? $N$ Engl $\mathcal{F}$ Med 1987;316:685-7.

3 Miller RA, Pople HE Jr, Myers JD. Internist I An experimental computer based diagnostic consultant for general internal medicine. $N$ Engl $\mathcal{F}$ Med $1982 \cdot 307: 468-78$

4 Auvert B, Aegerter PH, Van Look F, et al. A hand-held decision aid system designed for rural health workers. Comput Biomed Res 1986;19:80-9.

5 Salamon R, Blum B, Jorgensen M (eds). Tropicaid: a portable expert system for medical decision aid in developing countries. MEDINFO 86. Amsterdam: Elsevier, 1986:222-4.

6 Macartney FJ. Diagnostic logic. Br Med f 1987;295:1325-31.

7 Essex BJ. Diagnostic pathways in clinical medicine. Edinburgh: Churchill Livingstone, 1975.

8 Vickery DM, Fries JF. Take care of yourself. The consumer's guide to medical care. 2nd ed. Reading, Massachusetts: Addison-Wesley, 1981.

(Accepted 14 fuly 1988)

\title{
Molecular genetics in clinical practice: evolution of a DNA diagnostic service
}

\author{
A L Meredith, M Upadhyaya, P S Harper
}

\begin{abstract}
The development of a molecular genetics diagnostic service over a three year period was studied in a National Health Service region with a population of three million. Starting from a time when few diagnostic applications were possible, the number of disorders and the overall demand had grown rapidly. Conditions for which molecular genetic diagnosis had been provided included Duchenne and Becker muscular dystrophy, myotonic dystrophy, Huntington's disease, and cystic fibrosis. Of $\mathbf{4 0 5}$ requests for diagnosis, 151 (37\%) related to determination of carrier state, $187(46 \%)$ to determining the feasibility of future prenatal diagnosis, and 67 (17\%) were prenatal diagnostic biopsy samples, almost exclusively of first trimester chorion. DNA samples for future diagnostic use with a wide range of genetic disorders had also been banked.
\end{abstract}

The study showed a need for close integration with clinical genetics services to allow satisfactory genetic counselling and interpretation of risks.

\section{Introduction}

It is 10 years since the first human gene was cloned Institute of Medical Wales College of Medicine, Heath Park, Cardiff CF4 4XN

A L Meredith, PHD, M Upadhyaya, PHD, P S Harper, FRCP, professor

Correspondence and requests for reprints to: Dr Meredith. increased possibility for the diagnosis and prediction of genetic disorders for which the gene has been cloned or where closely linked markers exist. This development, though not its extent, was foreseen by some workers in molecular genetics, and three centres in the United Kingdom were funded for three years to evaluate applying the new advances by means of a diagnostic service.

We present a preliminary analysis of data collected during this pilot study in Cardiff, one of the three centres. Though the project has not yet been concluded, and there will be an independent evaluation of its acceptability and economic value, an assessment now is of value because the discipline is changing rapidly and there is pressure on many regions to develop their own services.

\section{The service}

Recombinant DNA techniques were established in our department in 1982 for research principally in relation to muscular dystrophies and other neurogenetic disorders. Diagnostic requests in relation to this research started to arise as early as $1983,{ }^{4}$ emphasising the need for a specific DNA diagnostic group. This was established in mid-1985 as a result of funding by the Welsh Office and Department of Health in connection with the "three centres" project.

A total of $£ 50000$ a year was provided, allowing the appointment of a senior scientist, a technician, and a part time data analyst. Running expenses were $£ 18000$ a year, and a similar initial sum was allocated for equipment costs. No funding was allocated for clinical or clerical aspects of the work nor for family tracing or sampling by genetic fieldworkers. 
The DNA diagnostic service is placed in our institute, which consists of an integrated medical genetics service providing a regional genetic counselling and laboratory service to the whole of Wales as well as an academic medical genetics research unit. Wales is a single health region in the National Health Service, with a population of 2.8 million and roughly 37000 births a year. Cardiff is the only medical teaching centre for the region.

The aims of setting up a DNA diagnostic service were to offer: (a) appropriate genetic counselling to families with a history of a genetic disorder for which molecular diagnostic applications were considered to be possible; $(b)$ testing of couples who requested prediction in a future pregnancy to determine heterozygosity and hence feasibility of future prenatal diagnosis; (c) prenatal diagnosis, normally based on chorion villus sampling, where this was requested and where family testing had shown it was possible; (d) presymptomatic diagnosis for asymptomatic adults at high risk of carrying an abnormal gene; $(e)$ extraction and banking of DNA from samples of tissue or blood for future analysis from those known to be affected or from other family members who were crucial for interpretation of DNA analysis in subsequent generations.

\section{Results}

The principal disorders for which prenatal diagnosis and carrier detection by DNA analysis have so far been offered are Duchenne and Becker muscular dystrophy, myotonic dystrophy, Huntington's disease, and cystic fibrosis. Table I gives the number of requests for diagnosis that have been referred to this centre during January 1986 to May 1988. Table II gives numbers for the principal diseases, and these are discussed in more detail below. Requests for genotyping to determine informativeness for future prenatal diagnosis, by establishing heterozygosity, comprised $187(46 \%)$ of total requests, prenatal diagnostic tests $67(17 \%)$, and testing for carrier and presymptomatic state 151 (37\%).

Prenatal diagnosis-Requests for prenatal diagnosis on pregnancies at high risk increased steadily over the period of the study, though numbers are still small relative to requests for establishing informativeness for testing a future pregnancy. Table III summarises our results on 65 cases analysed from chorion biopsies; 20 of these were sent to us from centres outside Wales. The figures for Huntington's disease relate to prenatal exclusion rather than to specific prenatal diagnosis. Two further pregnancies were analysed by amnio-

TABLE II-Molecular genetic analysis for principal genetic disorders fanuary 1986 to May 1988. Numbers of completed studies given

\begin{tabular}{lccc}
\hline \multicolumn{1}{c}{ Disorder } & $\begin{array}{c}\text { Heterozygote detection } \\
(\text { carrier and presymptomatic }) \\
(\mathbf{n}=151)\end{array}$ & $\begin{array}{c}\text { Informativeness for } \\
\text { prenatal diagnosis } \\
(\mathbf{n}=187)\end{array}$ & $\begin{array}{c}\text { Prenatal } \\
\text { diagnosis } \\
(\mathbf{n}=61)\end{array}$ \\
\hline Duchenne muscular dystrophy & 76 & 64 & 20 \\
Becker muscular dystrophy & 13 & 21 & 5 \\
Myotonic dystrophy & 27 & 18 & 6 \\
Huntington's disease & 35 & 61 & 19 \\
Cystic fibrosis & & 23 & 11 \\
\hline
\end{tabular}

TABLE III - Numbers of prenatal diagnoses in the first trimester using DNA analysis

\begin{tabular}{lcccc}
\hline \multicolumn{1}{c}{ Disorder } & $\begin{array}{c}\text { Total } \\
\text { No of } \\
\text { pregnancies } \\
(\mathbf{n}=65)\end{array}$ & $\begin{array}{c}\text { No of samples sent } \\
\text { from outside } \\
\text { Wales } \\
(\mathbf{n}=20)\end{array}$ & $\begin{array}{c}\text { Prediction } \\
\text { abnormal or } \\
\text { high risk } \\
(\mathbf{n}=20)\end{array}$ & $\begin{array}{c}\text { Prediction } \\
\text { normal or } \\
\text { low risk } \\
(\mathbf{n}=45)\end{array}$ \\
\hline $\begin{array}{l}\text { Duchenne muscular dystrophy } \\
\text { Becker muscular dystrophy }\end{array}$ & 20 & 4 & 6 & 14 \\
Myotonic dystrophy & 5 & 1 & 1 & 4 \\
Huntington's disease & 5 & 4 & 2 & 3 \\
Cystic fibrosis & 19 & 7 & 2 & 11 \\
Haemophilia A & 10 & 3 & 1 & 5 \\
\hline
\end{tabular}

centesis rather than by chorion biopsy. One was in a family with cystic fibrosis that was referred too late for chorion biopsy, and in the second (myotonic dystrophy) delay resulted from difficulty in obtaining an informative situation with the probes available.

DNA banking-DNA extraction from a variety of samples is fundamental to the service offered in Cardiff. Over the past year we received an average of 120 samples a month. These samples are mostly blood, but we routinely extract DNA from cultured cells, biopsy material, long term deep frozen tissue, and necropsy samples. Most of these samples are essential for an immediate request for diagnosis. A proportion, however, are received specifically for DNA banking (table IV). These have been coded separately since April 1987. Table IV shows that the diagnostic indications include a large proportion of disorders for which no immediate DNA investigations could be performed at the time of sampling.

TABLE IV-DNA banking for genetic disorders over one year, April 1987 to April 1988 (research samples excluded)

\begin{tabular}{lc}
\hline \multicolumn{1}{c}{ Diagnosis } & $\begin{array}{c}\text { No of samples taken } \\
(\mathbf{n}=758)\end{array}$ \\
\hline Huntington's disease & 215 \\
Duchenne muscular dystrophy & 73 \\
Becker muscular dystrophy & 27 \\
Facioscapulohumeral muscular dystrophy & 39 \\
Myotonic dystrophy & 35 \\
Myotubular myopathy & 29 \\
Cystic fibrosis & 36 \\
Phenylketonuria & 77 \\
Adult polycystic kidney disease & 57 \\
Osteogenesis imperfecta & 28 \\
Neurofibromatosis & 14 \\
Others (less than 10 samples, 31 disorders) & 128 \\
&
\end{tabular}

\section{DUCHENNE AND BECKER MUSCULAR DYSTROPHIES}

Our department was the first to apply DNA techniques to detect carriers of the $\mathrm{X}$ linked disorders Duchenne and Becker muscular dystrophies, ${ }^{2}$ to analyse the effects of flanking markers in improving the accuracy of carrier detection, ${ }^{6}$ and to show that the two disorders were likely to be allelic. ${ }^{7}$ A genetic register has been maintained for families in Wales for over 10 years, and samples have often been received from families outside our region. Thus it is not easy to distinguish the investigations that are carried out as part of our research activity from primary diagnostic requests. The approaches used have also evolved rapidly during the evaluation with our understanding of the gene for Duchenne muscular dystrophy. Initially, loosely linked flanking markers were used, followed by intragenic probes, such as pERT 87 and $\mathrm{XJ1}$, while the development of $\mathrm{cDNA}$ probes $^{8}$ now allows deletion analysis in about two thirds of cases.

Table V summarises our diagnostic experience in carrier detection. A total of 104 women ( 82 Duchenne, 22 Becker) were tested, in 19 of whom carrier risks were reduced to $1 \%$ or less; a further seven had risks reduced below 5\%. Among those 85 women who

TABLE $\mathrm{V}$-Molecular genetic analysis in potential carriers for Duchenne and Becker muscular dystrophies. Figures are numbers

\begin{tabular}{lccr}
\hline & $\begin{array}{c}\text { Duchenne } \\
\text { muscular } \\
\text { dystrophy }\end{array}$ & $\begin{array}{c}\text { Becker } \\
\text { muscular } \\
\text { dystrophy }\end{array}$ & Total \\
\hline Women at risk assessed & 82 & 22 & 104 \\
Risk reduced to 1\% or less & 18 & 1 & 19 \\
Risk reduced to under 5\% & 24 & 2 & 26 \\
$\begin{array}{l}\text { Risk raised to 95\% or more } \\
\text { Obligate carriers }\end{array}$ & 28 & 2 & 30 \\
$\begin{array}{l}\text { Molecular deletion detected } \\
\text { Total No informative for prenatal }\end{array} \quad 6$ & 9 & 15 \\
$\quad$ diagnosis & 9 & 10 & 19 \\
$\begin{array}{l}\text { Not informative for prenatal diagnosis } \\
\text { at time of study }\end{array}$ & 46 & 19 & 65 \\
& 18 & 2 & 20 \\
\hline
\end{tabular}


wished to proceed to prenatal diagnosis, including 15 obligatory carriers, 65 have so far been found to be informative, only 20 not being heterozygous for at least one polymorphism that would allow accurate $(95 \%)$ prediction for a pregnancy. Some of these were tested early in the programme and will prove informative when retested with new markers. In 19 cases a molecular deletion was detected, allowing a specific prenatal diagnosis to be offered; this number will be further increased when cDNA analysis is undertaken on all cases. Table III gives details on prenatal diagnostic tests.

\section{MYOTONIC DYSTROPHY}

Myotonic dystrophy, an autosomal dominant disorder that generally causes disability in adult life but also occurs in a severe congenital form when transmitted by affected women, has been a longstanding research interest of the department, but only diagnostic requests have been included here. These have principally been for detection of presymptomatic carriers and testing for informativeness as regards future prenatal diagnosis (27 and 18 completed analyses respectively). In contrast with Duchenne muscular dystrophy only linked markers are available since the gene itself has not yet been isolated. The six restriction fragment length polymorphisms defined by the closely linked APOC2 gene probe ${ }^{9}$ show pronounced linkage disequilibrium with each other, which has resulted in 23 additional families, though they are being extensively typed, remaining uninformative or partially informative. We are investigating other probes in close proximity to myotonic dystrophy with a view to diagnostic application.

\section{CYSTIC FIBROSIS}

Before 1986 our department did no appreciable research into cystic fibrosis, and requests for genetic counselling were relatively infrequent, this aspect being dealt with by our paediatric colleagues. Localisation of the gene on chromosome 7 in late $1985^{10}$ has produced a sudden increase in demand, necessitating DNA sampling and the construction of a register of families in Wales. Our priority was to type first the families with a living child with cystic fibrosis who were planning another pregnancy, and, secondly, other couples who were still of childbearing age. Until now carrier testing has been limited to family members, but the finding that the gene is strongly associated with a particular marker allele ${ }^{11}$ makes it also feasible to modify the carrier risk of unrelated partners. We routinely use up to seven restriction fragment length polymorphisms linked to cystic fibrosis at a distance of $1 \mathrm{cM}$ or less and find that in nearly all (94\%) families it is possible to alter the risk. In addition, two more restriction fragment length polymorphisms linked at $2 \mathrm{cM}$ and $4 \mathrm{cM}$ are available when necessary. Use of the polymerase chain reaction on DNA from samples such as buccal squames ${ }^{12}$ may have important implications for screening carriers in the population.

\section{HUNTINGTON'S DISEASE}

Genetic prediction in Huntington's disease is accompanied by ethical and practical problems relating to the consequences of detecting in a healthy person a gene that will inevitably result in a serious, progressive, and at present untreatable disorder. A register of affected people and individuals at risk has been kept in Wales for the past 15 years, ${ }^{13}$ but diagnostic application of linked DNA markers has been confined to the use since early 1987 of "exclusion testing" in pregnancy. This allows a couple to determine whether the "at risk" genotype has been transmitted to the pregnancy or not, without altering the risk for the parent concerned. Preliminary results of this approach have already been reported. ${ }^{5}$ We have now tested 61 couples to determine informativeness for exclusion testing in pregnancy. Nineteen pregnancies from 16 couples were tested by chorion biopsy, in 11 of which the disease was "excluded," the remaining eight being at increased risk and all parents of these choosing termination of the pregnancy.

A pilot evaluation of individuals who are presently asymptomatic and have requested risk alteration is now in progress. Data are not included here as this is a research evaluation and is at a preliminary stage.

Several new linked probes in the vicinity of the gene for Huntington's disease have recently become available, and we are applying up to 15 restriction fragment length polymorphisms in diagnostic requests. DNA analysis is now possible in over $95 \%$ of families. The limiting factor for predicting is the availability of DNA from relevant family members.

\section{Discussion}

The clearest result to emerge from our data is the steady growth and considerable volume of both the number of diagnostic tests requested and the range of disorders. At the beginning of the project the haemoglobinopathies were the only conditions for which molecular genetic diagnosis had been established,$^{14}$ though loosely linked genetic markers were available for the $\mathrm{X}$ linked muscular dystrophies.

A further relevant finding is that frequency of a disorder is not the only, or indeed the principal, factor in the demand for diagnosis. In some instances - for example, myotonic dystrophy and Huntington's disease-our previous research interests are likely to have increased the awareness among families and professional colleagues and resulted in referrals from outside Wales. In others, such as phenylketonuria and polycystic kidney disease, there has been minimal diagnostic demand so far despite previous family ascertainment. In the case of phenylketonuria the phenylalanine hydroxylase probe has been available for three years. The participation of our centre in the regional phenylketonuria screening service and clinic and the availability of effective treatment and prevention are likely to have influenced the perception of need by the families in this instance.

For two groups of disorders, the haemoglobinopathies and haemophilias, our unit has collaborated closely with colleagues already working specifically with these disorders, either in Cardiff (haemophilias) or Oxford (haemoglobinopathies). These diagnoses are hence correspondingly underrepresented in this study. As skills in molecular genetics spread through more specialist departments such collaborations will probably be more frequent; in both cases the close contact between the two units has proved helpful for ensuring satisfactory genetic counselling, sampling of appropriate family members, and organisation of chorionic villus sampling.

DNA banking is an important part of our diagnostic service. In some instances the indication was for an affected patient who was not expected to live (or who had just died), and whose relations were likely to request prediction using the results on that person. As table IV shows many of the disorders for which DNA banking was requested have no available molecular genetic diagnosis, while for others this has become available since the banking of the samples. In particular no DNA prediction was possible for cystic fibrosis until early 1986 since when diagnostic demand has increased rapidly. The pace of advances in molecular genetics makes such banking of great importance and emphasises the need for accurate record keeping and preservation of DNA samples. 
The results presented here do not cover the considerable work entailed in clinical diagnosis and genetic counselling, in home visits by genetic nurse fieldworkers, in telephone time organising prenatal diagnostic and other procedures, and in clerical support for producing written results and correspondence. We are fortunate in having a broadly based medical genetics department which has been able to absorb some of this load. The experience of our molecular genetics research group has provided advice and training for laboratory personnel that would not have been available in a unit lacking such skills, while the sharing of major equipment and joint ordering of reagents has also produced a hidden saving in costs.

\section{Future developments}

It is unlikely that the current pace of development in molecular genetics will slacken. Most major mendelian disorders are likely to be accurately mapped and some of the genes cloned within the next decade so that those currently included in the programme represent a small proportion only of the future demand. It is likely that part of the total load will be shared by other departments with knowledge of specific disease groups, and the workload may be reduced when unique changes are identified in the DNA of affected individuals, such as gene deletion or specific haplotypes, which are already proving useful in the $\mathrm{X}$ linked muscular dystrophies. Nevertheless, it is likely that diagnosis based on the family will remain important as seen in the haemoglobinopathies, where specific diagnosis has been available for some time.

Our experience of the past three years has provided valuable lessons in the organisation of a molecular genetics diagnostic service. We emphasise the importance of a close association with an established medical genetics service, which facilitates convenient interaction with clinical staff who primarily carry out genetic counselling, as well as with other laboratory genetics services such as cytogenetics. Being a regional service is also a strength. Whereas initially a larger population base might have been considered desirable for a specialised service of this type, the current volume and increase in the work suggests that a regional structure with a population of two to four million is probably right for a molecular genetics service, though close collaboration between units with specific skills for individual rare disorders will also be important.
Some wider aspects of the joint project, including the associated clinical workload, the economic factors, and the relationship with the overall genetics service are being assessed. All of these need to be analysed before the role of molecular genetic diagnosis in preventing genetic disorders can be accurately determined. However, the greater awareness of molecular genetic diagnosis and the increase in requests for diagnosis during the project suggest that it is going to play a major part in preventing many serious human inherited diseases.

We thank the collaborating groups at St Mary's Hospital, Manchester, and the Institute of Child Health, London, and all our colleagues in the Institute of Medical Genetics for their help during this work, especially L Lazarou, J Floyd, and K Roberts. Dr N S T Thomas supplied data on the X linked muscular dystrophies, while Drs L Al-Jader, A Norman, O Quarrell, and A Fryer helped with the clinical evaluation and counselling of families. We thank the Department of Health and the Welsh Office for financial support and their medical and scientific staff for their interest and encouragement.

1 Lawn RM, Fritsch EF, Parker RC, Blake G, Maniatis T. The isolation and characterization of linked $\alpha$ - and $\beta$-globin genes from a cloned library of characterization of linked $\alpha$ - and $\beta$ -
human DNA. Cell 1978;15:1157-74.

2 Murray JM, Davies KE, Harper PS, Meredith AL, Mueller CR, Williamson R. Linkage relationship of a cloned DNA sequence on the short arm of the X-chromosome to Duchenne muscular dystrophy. Nature 1982;300:69-71.

3 Anonymous. Human gene mapping 9. Cytogenet Cell Genet 1987;46:1-762.

4 Harper PS, O'Brien T, Murray JM, Davies KE, Pearson P, Williamson R. The use of linked DNA polymorphisms for genotype prediction in families with Duchenne muscular dystrophy. $\mathcal{F}$ Med Genet 1983;20:252-4.

5 Quarrell OWJ, Tyler A, Upadhyaya M, Meredith AL, Youngman S, Harper PS. Exclusion testing for Huntington's disease in pregnancy with a closely linked DNA marker. Lancet 1987; i:1281-3.

6 Williams H, Sarfarazi M, Brown C, Thomas N, Harper PS. The use of flanking markers in prediction for Duchenne muscular dystrophy. Arch Dis Child 1986;61:218-22.

7 Kingston HM, Thomas NST, Pearson PL, Sarfarazi M, Harper PS. Genetic linkage between Becker muscular dystrophy and a polymorphic DNA linkage between Becker muscular dystrophy and a polymorphic DNA

Forrest SM, Cross GS, Thomas NST, et al. Effective strategy for prenatal Forrest SM, Cross GS, Thomas NST, et al. Effective strategy for prenatal
prediction of Duchenne and Becker muscular dystrophy. Lancet 1987;ii: prediction.

9 Meredith AL, Huson SM, Lunt PW, et al. Application of a closely linked polymorphism of restriction fragment length to counselling and prenatal testing in families with myotonic dystrophy. Br Med $\mathcal{J}$ 1986;293:1353-6.

10 Wainwright BJ, Scambler PJ, Schmidtke J, et al. Localisation of cystic fibrosis locus to human chromosome 7 cen-q22. Nature 1985;318:384-5.

11 Estivill X, Farral M, Scambler P, et al. A candidate for the cystic fibrosis locus isolated by selection for methylation free islands. Nature 1987;326:840-5.

2 Lench N, Stanier P, Williamson R. Simple non-invasive method to obtain DNA for gene analysis. Lancet $1988 ; \mathrm{i}: 1356-8$.

13 Harper PS, Tyler A, Smith S, Jones P, Newcombe RG, McBroom V. A genetic register for Huntington's chorea in south Wales. $\mathcal{F}$ Med Genet 1982;19: $241-5$.

14 Weatherall DJ, Old JM. Antenatal diagnosis of the haemoglobin disorders by analysis of foetal DNA. Mol Biol Med 1983;1:151-5.

(Accepted 24 August 1988)

\section{MATERIA NON MEDICA}

\section{Learning the hard way}

"Very hot!" said an oriental voice sympathetically.

I nodded, sweating. The man, smartly dressed with a small attaché case, was walking beside me on the crowded Bangkok pavement. Obviously I was English, he remarked: in October he was coming to England to study. $\mathrm{He}$ mentioned a provincial university: "The best after Oxford and Cambridge, I think?" I politely agreed. He was a teacher but as today was a religious holiday he was going to his temple.

"You like to see? It's round the corner." Why not, I thought. "Too hot to walk," he said and hailed a $t u k-t u k$.

We roared down to the river and took a water taxi up a broad canal. With an unchanging grave expression he pointed out families bathing beside their wooden houses.

"No middle class in Bangkok - only rich and poor."

We alighted at a Buddhist temple, glittering red and gold, and walked reverently through its grounds. Hundreds of monks in saffron robes sat in the main building, some turning to watch us curiously. Over the loudspeakers an aged voice chanted a long prayer. Families ate lunch beside a wall containing cremated ashes and small memorials.
"They believe their relative's spirit will come and eat with them." My friend motioned me to wait and returned with a bowl of cut flowers. We removed our shoes and he placed his flowers among others in front of a shrine with a photograph of the temple's founder. "A great man," he said intensely.

Returning by water taxi, we stopped at a cafe. Over lunch, he talked of his village and told me what a privilege it was to practise his English with me. He ordered more beer than I wanted and refused to let me pay. We exchanged addresses. The colourful boat took us back across the river and stopped 20 yards from the quay.

"He needs money," said my friend, "and I do not have enough."

"How much?" said I, comprehending at last.

The boatman looked inscrutably at my friend, who looked at my wallet. The fare, it transpired, was nicely covered by all the money I had on me, leaving just enough for the tuk-tuk back to my hotel. My friend's address, I later discovered, was false. (Mine, fortunately, had been a post office box.) Next day, as a solitary sightseer, I was regularly approached by smartly dressed men. I stared blankly at them and pretended to be Scandinavian. JAMES OWEN DRIFE, senior lecturer in obstetrics and gynaecology, Leicester. 